\title{
A Recyclable Metal-Organic Framework as a Dual Detector and Adsorbent for Ammonia
}

\author{
Andrzej Gładysiak, ${ }^{[a]}$ Tu N. Nguyen, ${ }^{[a]}$ Jorge A. R. Navarro, ${ }^{[b]}$ Matthew J. Rosseinsky, ${ }^{[c]}$ and Kyriakos C. \\ Stylianou*[a]
}

\begin{abstract}
Recyclable materials for simultaneous detection and uptake of ammonia $\left(\mathrm{NH}_{3}\right)$ are of great interest due to the hazardous nature of $\mathrm{NH}_{3}$. The structural versatility and porous nature of metalorganic frameworks (MOFs) make them ideal candidates for $\mathrm{NH}_{3}$ capture. Herein, we report the synthesis of a water-stable and porous 3-dimensional Cu(II)-based MOF (SION-10) displaying a ship-in-a-bottle structure; the pores of the host SION-10 framework accommodate mononuclear Cu(II)-complexes. SION-10 spontaneously uptakes $\mathrm{NH}_{3}$ as a result of two concurrent mechanisms: chemisorption due to the presence of active $\mathrm{Cu}(\mathrm{II})$ sites and physisorption (bulk permanent porosity). The color of the material changes from green to blue upon $\mathrm{NH}_{3}$ capture, with the shifts of the absorption bands clearly seen at $\mathrm{NH}_{3}$ concentrations as low as 300 ppm. SION-10 can be recovered upon immersion of SION-10 $\mathrm{NH}_{3}$ in liquid water and can be further reused for $\mathrm{NH}_{3}$ capture for at least three cycles.
\end{abstract}

Ammonia $\left(\mathrm{NH}_{3}\right)$ is a corrosive and toxic gas with a strong odor that is widely produced and used in industries. In industrial settings, $25 \mathrm{ppm}$ of $\mathrm{NH}_{3}$ is the exposure limit recommended by the US Occupational Safety and Health Administration, ${ }^{[1]}$ and exposure to up to $300 \mathrm{ppm}$ of $\mathrm{NH}_{3}$ can cause serious health issues. ${ }^{[2]}$ Meanwhile, there is still a very high demand for $\mathrm{NH}_{3}$ at the industrial scale as reflected by its production of 145 million tons in 2014. ${ }^{[3]} \mathrm{NH}_{3}$ is an important raw material for the manufacturing of large numbers of chemicals including fertilizers, dyes, plastics, and pharmaceuticals, ${ }^{[4]}$ and is considered as a potential carbon-free green fuel due to its high energy density and its lower cost of production, storage, and delivery compared to hydrogen. ${ }^{[5]}$ Both the danger and usefulness of $\mathrm{NH}_{3}$ have motivated researchers to develop economical and responsive materials that can selectively detect and capture $\mathrm{NH}_{3}$; for example, $\mathrm{NH}_{3}$ sensors based on catalytic metals ${ }^{[6]}$ and

[a] A. Gładysiak, Dr. T. N. Nguyen, Dr. K. C. Stylianou Laboratory of Molecular Simulation (LSMO) Institut des Sciences et Ingénierie Chimiques (ISIC) Ecole Polytechnique Fédérale de Lausanne (EPFL Valais) Rue de l'Industrie 17, 1951 Sion (Switzerland)

E-mail: kyriakos.stylianou@epfl.ch

[b] Prof. Dr. J. A. R. Navarro

Departamento de Química Inorgánica

Universidad de Granada

Av. Fuentenueva S/N, 18071 Granada (Spain)

[c] Prof. Dr. M. J. Rosseinsky

Department of Chemistry

University of Liverpool

Liverpool, L69 7ZD (UK)

Supporting information for this article is given via a link at the end of the document. conducting polymers ${ }^{[7]}$ have been reported, whilst porous materials such as activated carbons, ${ }^{[8]}$ organic polymers, ${ }^{[9]}$ covalent organic frameworks, ${ }^{[10]}$ and $\mathrm{MOFs}^{[11]}$ are known as efficient $\mathrm{NH}_{3}$ sorbents.

MOFs are crystalline materials prepared by the selfassembly of metal ions or clusters with organic ligands to form porous extended structures. ${ }^{[12]}$ MOFs are characterized by high porosity, with some of them possessing the highest volume and surface area, and lowest crystal density among all materials known to date. ${ }^{[13]}$ The immense choice of metal ions or clusters and ligands offers vast opportunities to rationally design and synthesize MOFs with specific functionalities for targeted applications in areas of gas storage and separation, ${ }^{[14]}$ catalysis, ${ }^{[15]}$ sensing, ${ }^{[16]}$ non-linear optics, ${ }^{[17]}$ ferroelectricity, ${ }^{[18]}$ magnetism, ${ }^{[19]}$ and conductivity. ${ }^{[20]}$ Recently, there is an increasing interest in developing porous and robust MOFs for the selective detection, capture and destruction of harmful molecules including toxic industrial chemicals $\left(\mathrm{SO}_{2}\right.$ and $\left.\mathrm{NH}_{3}\right)$, and chemical warfare agents (sarin, sulfur mustard, and dimethyl methylphosphonate). ${ }^{[21]}$

Due to the high basicity and corrosivity of $\mathrm{NH}_{3}$, the most challenging task in the MOF research area is to develop sorbents and detectors that can efficiently capture and detect $\mathrm{NH}_{3}$, and can be recycled while retaining their structural integrity. ${ }^{[22]}$ Recently, Dincă et al. have reported mesoporous and robust azolate-based MOFs exhibiting open $\mathrm{Mn}(\mathrm{II}), \mathrm{Co}(\mathrm{II})$, and $\mathrm{Ni}(\mathrm{II})$ sites which display high and reversible $\mathrm{NH}_{3}$ uptake. ${ }^{[11]}$ The strategy of employing azolates to increase the stability of MOFs, initially addressed by Rosi et al., ${ }^{[23]}$ motivated us to synthesize SION-10 by employing adenine in the MOF structure. We chose to use $\mathrm{Cu}(\mathrm{II})$ in which, along with other d-element cations in MOFs, has the potential to introduce strong interactions with $\mathrm{NH}_{3}{ }^{\left[22,{ }^{24]}\right.}$ SION-10 is a 3-dimensional MOF based on the earth abundant $\mathrm{Cu}(\mathrm{II})$ and readily available benzene-1,3,5-tricarboxylic acid and adenine ligands. It exhibits reversible $\mathrm{NH}_{3}$ uptake, and displays a visible and reversible color change upon adsorption and desorption of $\mathrm{NH}_{3}$.

SION-10 was synthesized hydrothermally after mixing $\mathrm{CuCO}_{3}$ with 1,3,5-benzenetricarboxylic acid $\left(\mathrm{H}_{3} \mathrm{btc}\right)$ and adenine (9Hade) (see SI Section 1 for the synthesis details) in pure water for 48 hours at $100{ }^{\circ} \mathrm{C}$. The crystals obtained were characterized by single-crystal X-ray diffraction (SCXRD). SION-10 with the formula of $\quad\left[\mathrm{Cu}_{4}(\mathrm{btc})_{2}\right.$ (ade)(1Hade) $\left(\mu_{3}-\right.$ $\left.\mathrm{OH})\left(\mathrm{H}_{2} \mathrm{O}\right)_{3}\right] \cdot 0.4\left[\mathrm{Cu}(\text { ade })_{2}\left(\mathrm{H}_{2} \mathrm{O}\right)_{4}\right] \cdot 10.5\left(\mathrm{H}_{2} \mathrm{O}\right)$ crystallizes in the triclinic space group $P^{-1}$ (SI Section 3 ), and comprises three components: $i$ a 3-dimensional host framework $\left[\mathrm{Cu}_{4}(\mathrm{btc})_{2}(\right.$ ade $\left.)(1 \mathrm{Hade})\left(\mu_{3}-\mathrm{OH}\right)\left(\mathrm{H}_{2} \mathrm{O}\right)_{3}\right]$, ii. guest mononuclear complexes that are partially occupying the void channels within the host SION-10 - 0.4[Cu(ade $\left.)_{2}\left(\mathrm{H}_{2} \mathrm{O}\right)_{4}\right]$ (Figure 1), and iii. highly disordered guest $\mathrm{H}_{2} \mathrm{O}$ solvent molecules. The host framework of SION-10 is based on Cu-paddlewheel units, in which two Cu1 
atoms are bridged by two deprotonated ade ${ }^{-}$ligands via an $\eta^{1}: \eta^{1}$ binding mode through their N3 and N9 atoms (ade ${ }^{-}$colored in green - Figure 1a). The neutral 1 Hade ligand is coordinated via $\mathrm{N} 7$ to the axial sites of the Cu-paddlewheel (1Hade colored in orange - Figure 1a). The coordination of the paddlewheel is completed by the two bridging carboxylates from two crystallographically equivalent $\mathrm{btc}^{3-}$ ligands. The Cupaddlewheel units are connected to each other via a tetranuclear Cu-cluster, $\mathrm{Cu}_{4}\left(\mu_{3}-\mathrm{OH}\right)_{2}$ (Figure $1 \mathrm{~b}$ ), constructed from four $\mathrm{Cu}(\mathrm{II})$ centers (two Cu2 and two Cu3) linked by two $\mu_{3}$ hydroxo groups. ${ }^{[25]}$ All $\mathrm{Cu} 2$ and Cu3 display a square pyramidal coordination geometry. The apical positions of these pyramids are occupied by $\mathrm{H}_{2} \mathrm{O}$ molecules coordinated to $\mathrm{Cu}(\mathrm{II})$ through considerably long bonds (Cu2-O2 2.431(6) Å, Cu3-O3 2.424(6) A). A single $\mathrm{Cu} 4$ atom, also with a square pyramidal coordination geometry, bonds to two btc ${ }^{3-}$ ligands (monodentate - yellow and bidentate - pink), one ade ${ }^{-}$and one $\mathrm{H}_{2} \mathrm{O}$ molecule (Cu4-O4 2.211(0) $\AA$ - Figure 1c), and acts as a link between Cupaddlewheel units and tetranuclear Cu-clusters. The host framework of SION-10 displays an accessible volume of $37.9 \%$, as determined by PLATON. ${ }^{[26]}$

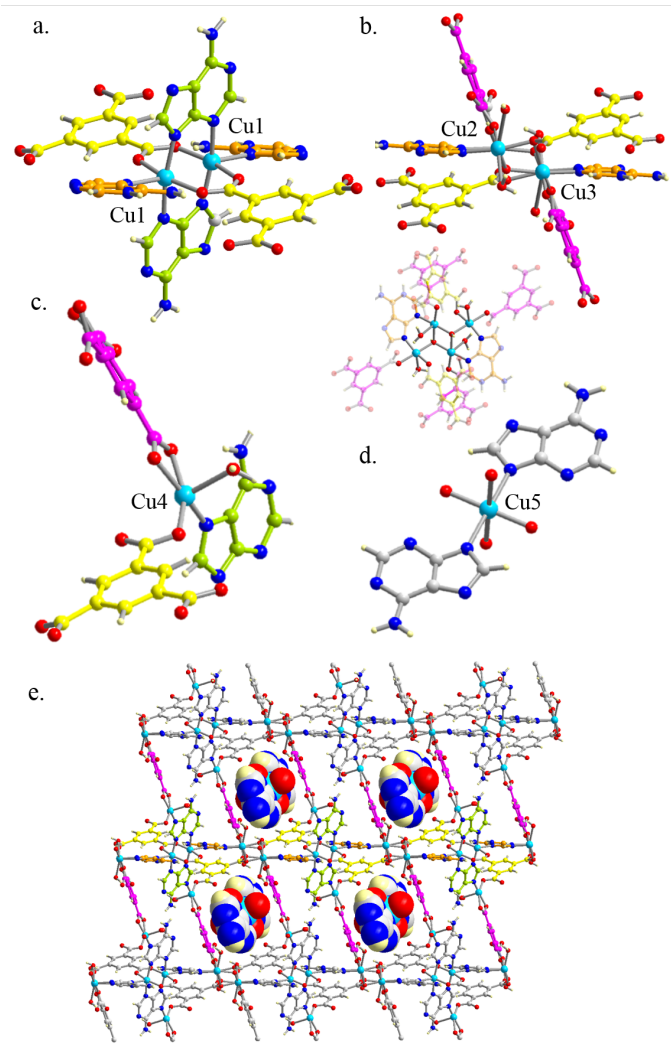

Figure 1. The structure of SION-10 consists of: a. Cu1-paddlewheel units which are linked to b. Cu2Cu3 tetranuclear clusters $\mathrm{Cu}_{4}\left(\mu_{3}-\mathrm{OH}\right)_{2}$ and c. mononuclear $\mathrm{Cu} 4$ to extend the structure in 3-dimensions. $\mathrm{d}$ and e. The pores of the host SION-10 accommodate guest mononuclear Cu5-complexes generating a material with ship-in-a-bottle structure. Atom color code: $\mathrm{C}$ gray, $\mathrm{H}$ pale yellow, $\mathrm{N}$ blue, $\mathrm{O}$ red, Cu cyan.
The cavities of the host SION-10 framework are occupied by mononuclear complexes with the formula of $\left[\mathrm{Cu}(\text { ade })_{2}\left(\mathrm{H}_{2} \mathrm{O}\right)_{4}\right]$ present with $80 \%$ partial occupancy (Figures 1d, and S3). The octahedrally coordinated Cu5 of the complex displays a JahnTeller distortion with two long $\mathrm{Cu}-\mathrm{N}($ ade) bonds $(2.226(17) \AA)$, two long $\mathrm{Cu}-\mathrm{OH}_{2}$ bonds (2.24(2) $\AA$ ), and two short $\mathrm{Cu}-\mathrm{OH}_{2}$ bonds $(1.941(14) \AA)$ (Figure 1d). The complex displays $\Pi-\pi$ stacking interactions between the pyrimidine ring of the ade $^{-}$ group and the phenyl ring of the btc ${ }^{3-}$ ligand with a distance of about $3.7 \AA$ (Figure S4), and is involved in an array of hydrogen bonds that stabilize its position within the framework cavities (Figure S5). Our attempts to wash the $\mathrm{Cu}$ (II)-complexes out were not successful, confirming that they cannot be removed from the host SION-10 framework. Interestingly, molecular crystals of $\mathrm{Cu}(\mathrm{ade})_{2}\left(\mathrm{H}_{2} \mathrm{O}\right)_{4}$ are not known, and the theoretically predicted structure of this complex ${ }^{[27]}$ is markedly different from the one reported in this work. Thus, SION-10 represents a typical example of a ship-in-a-bottle material. It is worth noting here that although the encapsulation of molecular species in the pores of a MOF is known, ${ }^{[28]}$ the direct observation of them as a part of a refined crystal structure is rather rare. ${ }^{[2]}$ The accessible volume of SION-10 (with the complexes present within the channels) was found to be $20.3 \%,{ }^{[26]}$ revealing that the complexes occupy nearly half of the accessible volume of the host-framework voids.

The phase purity of SION-10 was confirmed by powder Xray diffraction (PXRD), scanning electron microscopy (SEM) and elemental analysis (EA), whereas the thermogravimetric (TGA) profile coupled with the variable-temperature (VT) PXRD study revealed the thermal stability of SION-10. The PXRD pattern of SION-10 (Figure 2a) can be indexed to unit-cell parameters consistent with the parameters obtained from SCXRD (SI Section 5a). SEM images reveal only one type of crystal morphology (Figure S14). Elemental and inductively coupled plasma (ICP) analyses confirmed that the $\left[\mathrm{Cu}(\text { ade })_{2}\left(\mathrm{H}_{2} \mathrm{O}\right)_{4}\right]$ complex is not $100 \%$ present within the pores as the composition of SION-10 can fit to the formula derived from the SCXRD data (SI Section 5c). FTIR spectra show characteristic features originating from both
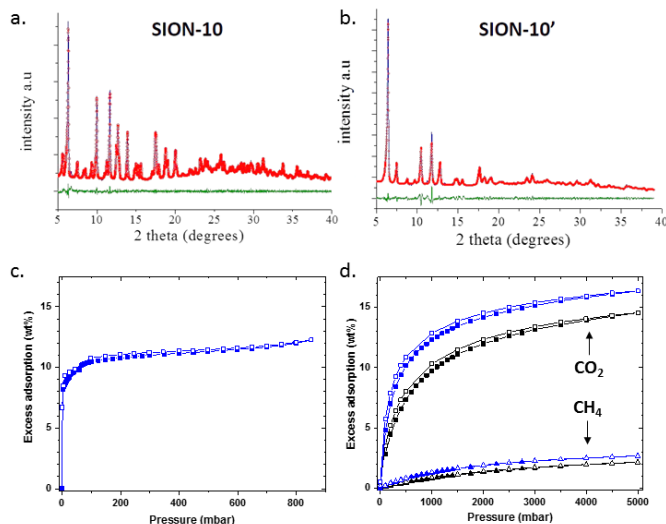

Figure 2. Le Bail fits of a. SION-10 and b. SION-10' collected at $298 \mathrm{~K}$ using the $\mathrm{Cu} K_{\alpha}$. The blue plots represent the experimental data, the red dots show the refined Le Bail profiles while the green plots represent the difference between them. SION-10' is porous to: c. $\mathrm{N}_{2}$ at $77 \mathrm{~K}$ and 900 mbar and d. $\mathrm{CO}_{2}$ 
(top two plots) and $\mathrm{CH}_{4}$ (bottom two plots) at 273 (blue plots) and $298 \mathrm{~K}$ (black plots) and 5000 mbar. In c. and d. full symbols represent adsorption, while the empty ones show the desorption.

ligands present in the structure of SION-10 (Figure S11). The TGA profile of SION-10 shows that the coordinated and guest $\mathrm{H}_{2} \mathrm{O}$ molecules can be removed in the temperature range of 30 $265{ }^{\circ} \mathrm{C}$ with the total loss of $20.8 \%$ (Figure S9). The weight loss observed in TGA is in good agreement with the weight loss calculated from the EA $(20.0 \%)$. Above $250{ }^{\circ} \mathrm{C}$ a substantial decrease in crystallinity is observed from the VT PXRD study (Figure S6) and the decomposition of SION-10 starts at $295^{\circ} \mathrm{C}$. As confirmed by PXRD (Figure S8) SION-10 is stable in liquid water as well as in acidic and basic aqueous solutions, thus confirming its hydrolytic stability.

The activated SION-10' was generated by heating the assynthesized SION-10 at $120^{\circ} \mathrm{C}$ under vacuum $\left(10^{-6} \mathrm{mbar}\right)$. The weight loss of $19.8 \%$ is consistent with the weight loss observed by TGA and EA. The PXRD pattern of SION-10' (Figure 2b) shows the retention of crystallinity and Le Bail fits revealed that the unit cell is contracted by $3.5 \%$ compared to the cell parameters of SION-10 (SI Section 5a). When SION-10' is exposed to the atmosphere for 1-2 hours or is immersed in liquid $\mathrm{H}_{2} \mathrm{O}$ (10 mins), SION-10 can be recovered. This suggests that SION-10' with open $\mathrm{Cu}(\mathrm{II})$ sites has high affinity for $\mathrm{H}_{2} \mathrm{O}$, and thus the re-coordination of $\mathrm{H}_{2} \mathrm{O}$ molecules to $\mathrm{Cu}$ (II) leads in the generation of the ordered SION-10 structure.

SION-10' is permanently porous to $\mathrm{N}_{2}$ at $77 \mathrm{~K}$ and 1 bar, exhibiting a reversible type I sorption behavior characteristic for microporous materials (Figure 2c). Application of the BrunauerEmmett-Teller (BET) model in the relative pressure $p / p^{0}$ range of $0.02-0.22$ results in a surface area of $\sim 300 \mathrm{~m}^{2} / \mathrm{g}$. The calculated pore volume of SION-10' is $0.138 \mathrm{~cm}^{3} / \mathrm{g}$, which is in good agreement with the pore volume derived from the single crystal data of the static structure of SION-10 $\left(0.132 \mathrm{~cm}^{3} / \mathrm{g}\right)$. SION-10' is porous to $\mathrm{CO}_{2}$ and $\mathrm{CH}_{4}$ at 273 and $298 \mathrm{~K}$ (type I isotherms, Figure $2 \mathrm{~d}$ ) and the isosteric heats of adsorption $Q_{\mathrm{st}}$ at zero coverage derived from the virial-type expression are 30.8 $\mathrm{kJ} / \mathrm{mol}$ for $\mathrm{CO}_{2}$ and $21.3 \mathrm{~kJ} / \mathrm{mol}$ for $\mathrm{CH}_{4}$.

Since the complexes do not block the porosity in SION-10' where open $\mathrm{Cu}(\mathrm{II})$ are present, and both polar and non-polar molecules can diffuse in the accessible voids, we subjected SION-10' to $\mathrm{NH}_{3}$ adsorption, with the $\mathrm{NH}_{3}$ vapor generated by evaporation of a $25 \%$ ammonia solution at room temperature. Upon exposing the green powder of SION-10' to $\mathrm{NH}_{3}$ vapor, a color change was immediately noticed and the green color changed to blue, whilst its shade deepened over a loading period of 30 mins (Figure 3c, inset). The formula of SION$10 \supset \mathrm{NH}_{3} \quad(30$ mins loading $)$ corresponds to $\left[\mathrm{Cu}_{4}(\mathrm{btc})_{2}\right.$ (ade)(1 Hade) $\left(\mu_{3}-\right.$

$\left.\mathrm{OH})\left(\mathrm{NH}_{3}\right)_{3}\right] \cdot 0.4\left[\mathrm{Cu}(\text { ade })_{2}\left(\mathrm{NH}_{3}\right)_{4}\right] \cdot 4\left(\mathrm{NH}_{3}\right) \cdot 6.5\left(\mathrm{H}_{2} \mathrm{O}\right)$, revealing that the amount of chemisorbed $\mathrm{NH}_{3}$ was $6.37 \mathrm{mmol} / \mathrm{g}$ (SI Section $5 \mathrm{c}$ and Figure S10). $\mathrm{NH}_{3}$ molecules displace all $\mathrm{H}_{2} \mathrm{O}$ ligands previously coordinated to $\mathrm{Cu}(\mathrm{II})$, and a part of non-coordinated $\mathrm{H}_{2} \mathrm{O}$ guest molecules. In order to further evaluate the capability of SION-10' to selectively capture $\mathrm{NH}_{3}$, we have performed a breakthrough experiment using a $10 \mathrm{~mL} \mathrm{~min}^{-1}$ flow of $\mathrm{N}_{2} / \mathrm{NH}_{3}$ (9:1) gas mixture at $303 \mathrm{~K}$ (Figure 3a). At the $\mathrm{NH}_{3}$ partial pressure of 0.1 bar SION-10' exhibited the adsorption capacity of $27.3 \mathrm{mmol} / \mathrm{g}$. In a separate experiment, the adsorption capacity of SION-10' at the $\mathrm{N}_{2}$ partial pressure of 0.9 bar and at $303 \mathrm{~K}$ was investigated (Figure S13). The amount of $\mathrm{N}_{2}$ adsorbed $(0.170 \mathrm{mmol} / \mathrm{g})$ was significantly lower than that of $\mathrm{NH}_{3}$, resulting in a $\mathrm{NH}_{3} / \mathrm{N}_{2}$ selectivity factor of 1440 . This result is indicative of a selective and strong interaction of $\mathrm{NH}_{3}$ molecules with SION-10' due to chemisorption (presence of active $\mathrm{Cu}(\mathrm{II})$ centers) and physisorption (narrow pores of SION-10'), and places SION-10' among materials with the highest $\mathrm{NH}_{3}$ capacity reported up to date..$^{[9,11]}$

Interestingly, the color change experienced by the $\mathrm{NH}_{3}$ loaded SION-10' was also observed when the as-made SION-10 was exposed to $\mathrm{NH}_{3}$ vapors. The immersion of the blue SION$10 \mathrm{NH}_{3}$ in liquid water resulted in the isolation of a green material suggesting that SION-10 could potentially be recovered. The PXRD patterns show that although the crystallinity of SION$10 \mathrm{DH}_{3}$ is reduced to a significant degree, the recovered material displays the same pattern as with SION-10, confirming the regeneration of SION-10 (Figure S7). The FTIR spectrum of SION-10 $\mathrm{NH}_{3}$ (Figure 3b) shows a nearly identical pattern with that of SION-10 with characteristic bands at $3400-3300 \mathrm{~cm}^{-1}$

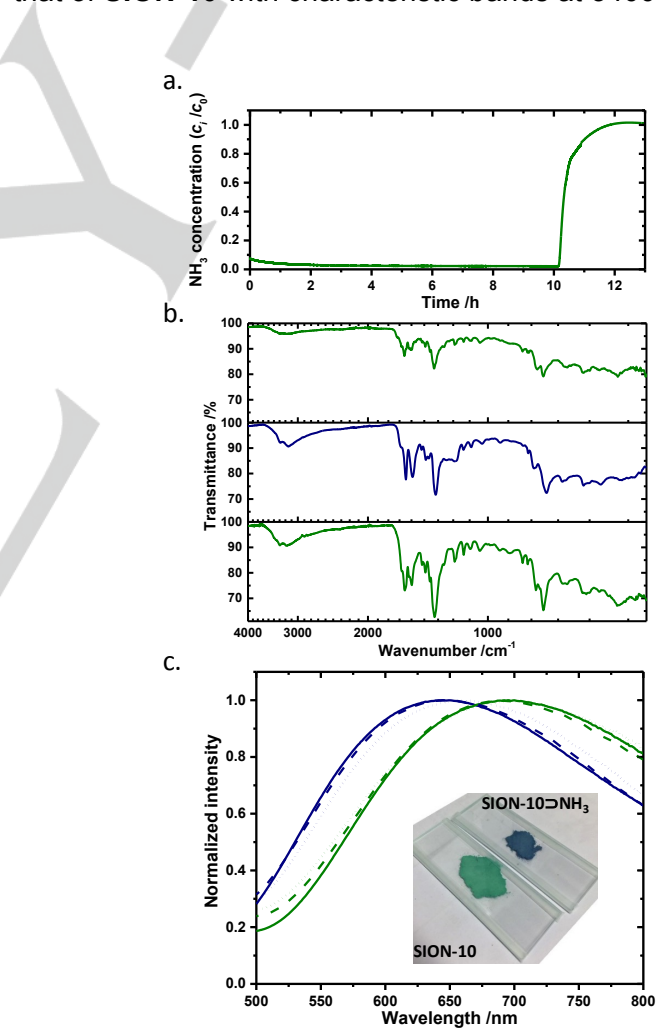

Figure 3. a. Breakthrough profile of $\mathrm{N}_{2} / \mathrm{NH}_{3}(9: 1)$ gas mixture at $303 \mathrm{~K}$ over SION-10'. b. FTIR spectra of the as-made SION-10 (top), SION-10 $\mathrm{NH}_{3}$ (middle) and recovered SION-10 (bottom) upon immersion of SION-10 $\mathbf{N H}_{3}$ in liquid $\mathrm{H}_{2} \mathrm{O}$, c. UV/Vis spectra of SION-10 (green plots) and SION-10 $\mathrm{NH}_{3}$ (blue plots) and cycling $\mathrm{NH}_{3}$ adsorption/desorption (first, second, and third uptake/regeneration cycles are shown in solid, dash, and dot lines, respectively). Inset: a photograph showing the color difference between SION10 and SION-10つ $\mathrm{NH}_{3}$ 
and $1640 \mathrm{~cm}^{-1}$, corresponding to the $\mathrm{N}-\mathrm{H}, \mathrm{O}-\mathrm{H}$, and $\mathrm{C}=\mathrm{O}$ stretching bands of the ade ${ }^{-}$, the $\mathrm{OH}^{-}$bridge/ $\mathrm{H}_{2} \mathrm{O}$ molecule, and the $\mathrm{C}=\mathrm{O}$ of the $\mathrm{btc}^{3-}$ ligand, suggesting that despite the low crystallinity it has the same structural fingerprint as SION-10. To further investigate the impact of $\mathrm{NH}_{3}$ uptake by SION-10 and its regeneration, the UV/Vis diffuse reflectance spectra were collected (Figure 3c). The UV/Vis spectra revealed a blue-shift of $\sim 70 \mathrm{~nm}$ of the $\mathrm{Cu}(\mathrm{II}) d-d$ transition band of SION-10 $\supset \mathrm{NH}_{3}$ compared to SION-10, suggesting the formation of new $\mathrm{Cu}-\mathrm{NH}_{3}$ bonds that are formed after the stronger-field $\mathrm{NH}_{3}$ ligands substitute the weak-field $\mathrm{H}_{2} \mathrm{O}$ ligands bound to $\mathrm{Cu}(\mathrm{II})$ centers. The recovered SION-10 displayed a comparable absorption band compared to the pristine SION-10, indicating that SION-10 could be recycled, and we successfully performed three $\mathrm{NH}_{3}$ adsorption-desorption $\mathrm{NH}_{3}$ cycles (Figure $3 \mathrm{c}$ ). Previous studies demonstrated that the presence of open metal sites within MOFs are key factors for the capture of $\mathrm{NH}_{3}$. However, MOFs endowed with open metal sites were shown to reduce their porosity and crystallinity to a considerable extent when loaded with $\mathrm{NH}_{3}$ vapors. ${ }^{[22]}$ For SION-10, we strongly believe that the combination of narrow pores generated from the presence of the complexes, and the presence of active $\mathrm{Cu}$ (II) sites are the key factors for the efficient capture of $\mathrm{NH}_{3}$.

The substantial green-to-blue color change was not observed with other gases (such as $\mathrm{CO}_{2}, \mathrm{~N}_{2}$ and $\mathrm{CH}_{4}$ ) suggesting that SION-10 can also act as a selective detector for $\mathrm{NH}_{3}$ vapor. When $5 \mathrm{mg}$ of SION-10 were exposed to controlled atmospheres of $\mathrm{NH}_{3}$ with concentrations of 300 and $600 \mathrm{ppm}$, the shifts of the absorption bands were clearly observed (Figure $\mathrm{S} 12$ ), indicating the relatively high sensitivity of SION-10 toward $\mathrm{NH}_{3}$. In addition, the fast response time, i.e. immediate color changes, ensures that SION-10 can quickly detect the presence of $\mathrm{NH}_{3}$ in the atmosphere. The high thermal and hydrolytic stability together with the uptake of $\mathrm{NH}_{3}$, and its recyclability confirm that SION-10 can be potentially used as a dual detector and adsorbent for $\mathrm{NH}_{3}$.

In conclusion, we report the synthesis of a ship-in-a-bottle SION-10 material that is stable in water, and upon activation it is porous to $\mathrm{N}_{2}, \mathrm{CO}_{2}$ and $\mathrm{CH}_{4}$. The presence of the mononuclear $\mathrm{Cu}$ (II) complexes decorate the pores of the host SION-10' with active $\mathrm{Cu}(\mathrm{II})$ sites that allow $\mathrm{NH}_{3}$ to be chemisorbed. SION-10' adsorbs up to a paramount value of $27.3 \mathrm{mmol}$ of $\mathrm{NH}_{3}$ per gram (chemisorption and physisorption) which is one of the highest $\mathrm{NH}_{3}$ uptake reported to date. The high sensitivity and selectivity of SION-10 toward $\mathrm{NH}_{3}$ makes SION-10 the first MOF that can quickly uptake $\mathrm{NH}_{3}$, easily regenerated and reused. In addition, it can detect $\mathrm{NH}_{3}$ at concentrations as low as 300 ppm.

This work demonstrates a step forward toward the discovery of versatile, easily prepared and recyclable MOFs acting as dual detectors and adsorbents for $\mathrm{NH}_{3}$ and further synthetic efforts in developing novel porous and water stable MOFs sensitive to $\mathrm{NH}_{3}$ concentrations lower than $300 \mathrm{ppm}$ are in progress.

\section{Acknowledgements}

KCS and TNN thank Swiss National Science Foundation (SNF) for funding under the Ambizione Energy Grant
n.PZENP2_166888. The authors are grateful for accessing BM31, ESRF and 119, DLS for powder and single-crystal X-ray diffraction data collection. JARN thanks the Spanish Ministry of Economy (CTQ2014-53486-R) and the European Union FEDER funding.

Keywords: metal-organic framework • ammonia • recyclability • ship-in-a-bottle $\cdot$ capture $\cdot$ detection

[1] National Institute for Occupational Safety and Health, 1992.

[2] in The MAK-Collection for Occupational Health and Safety, WileyVCH Verlag GmbH \& Co. KGaA, 2002.

[3] U.S. Geological Survey, 2017.

[4] R. Radermacher, K. Kim, Int. J. Refrig. 1996, 19, 61-69.

[5] R. Lan, S. Tao, Front. Energy Res. 2014, 2, $1-4$.

[6] I. Lundström, A. Spetz, F. Winquist, U. Ackelid, H. Sundgren, Sens. Actuators B Chem. 1990, 1, 15-20.

[7] A. L. Kukla, Y. M. Shirshov, S. A. Piletsky, Sens. Actuators B Chem. 1996, 37, 135-140.

[8] A. Qajar, M. Peer, M. R. Andalibi, R. Rajagopalan, H. C. Foley, Micropor. Macropor. Mater. 2015, 218, 15-23.

[9] J. F. Van Humbeck, T. M. McDonald, X. Jing, B. M. Wiers, G. Zhu, J. R. Long, J. Am. Chem. Soc. 2014, 136, 2432-2440.

C. J. Doonan, D. J. Tranchemontagne, T. G. Glover, J. R. Hunt, O. M. Yaghi, Nat. Chem. 2010, 2, 235-238.

[11] A. J. Rieth, Y. Tulchinsky, M. Dincă, J. Am. Chem. Soc. 2016, 138, 9401-9404.

[12] a) O. M. Yaghi, M. O'Keeffe, N. W. Ockwig, H. K. Chae, M. Eddaoudi, J. Kim, Nature 2003, 423, 705-714; b) H. Furukawa, K. E. Cordova, M. O'Keeffe, O. M. Yaghi, Science 2013, 341, 1230444.

[13] a) O. K. Farha, I. Eryazici, N. C. Jeong, B. G. Hauser, C. E. Wilmer, A. A. Sarjeant, R. Q. Snurr, S. T. Nguyen, A. Ö. Yazaydın, J. T. Hupp, J. Am. Chem. Soc. 2012, 134, 15016-15021; b) H. Furukawa, Y. B. Go, N. Ko, Y. K. Park, F. J. Uribe-Romo, J. Kim, M. O’Keeffe, O. M. Yaghi, Inorg. Chem. 2011, 50, 9147-9152.

[14] a) S. Ma, H.-C. Zhou, Chem. Commun. 2010, 46, 44-53; b) K. Sumida, D. L. Rogow, J. A. Mason, T. M. McDonald, E. D. Bloch, Z. R. Herm, T.-H. Bae, J. R. Long, Chem. Rev. 2012, 112, 724-781. a) Y.-B. Huang, J. Liang, X.-S. Wang, R. Cao, Chem. Soc. Rev. 2017, 46, 126-157; b) A. H. Chughtai, N. Ahmad, H. A. Younus, A. Laypkov, F. Verpoort, Chem. Soc. Rev. 2015, 44, 6804-6849; c) M. Ranocchiari, J. A. van Bokhoven, Phys. Chem. Chem. Phys. 2011, 13, 6388-6396.

[16] a) L. E. Kreno, K. Leong, O. K. Farha, M. Allendorf, R. P. Van Duyne, J. T. Hupp, Chem. Rev. 2012, 112, 1105-1125; b) Z. Hu, B. J. Deibert, J. Li, Chem. Soc. Rev. 2014, 43, 5815-5840; c) S. E. Miller, M. H. Teplensky, P. Z. Moghadam, D. Fairen-Jimenez, Interface Focus 2016, 6, 20160027; d) D. Wang, Q. Tan, J. Liu, Z Liu, Dalton Trans. 2016, 45, 18450-18454; e) X. Liu, W. Fu, E. Bouwman, Chem. Commun. 2016, 52, 6926-6929; f) M. Andrzejewski, A. Katrusiak, J. Phys. Chem. Lett. 2017, 8, 279-284.

[17] L. R. Mingabudinova, V. V. Vinogradov, V. A. Milichko, E. HeyHawkins, A. V. Vinogradov, Chem. Soc. Rev. 2016, 45, 5408-5431. W. Zhang, R. G. Xiong, Chem. Rev. 2012, 112, 1163-1195.

[19] a) A. D. Katsenis, E. K. Brechin, G. S. Papaefstathiou, in Encyclopedia of Inorganic and Bioinorganic Chemistry, John Wiley \& Sons, Ltd, 2011; b) M. Kurmoo, Chem. Soc. Rev. 2009, 38, 1353-1379.

a) L. Sun, M. G. Campbell, M. Dincă, Angew. Chem. Int. Ed. 2016, 55, 3566-3579; b) P. Ramaswamy, N. E. Wong, G. K. Shimizu, Chem. Soc. Rev. 2014, 43, 5913-5932; c) S. Horike, D. Umeyama, S. Kitagawa, Acc. Chem. Res. 2013, 46, 2376-2384; d) A. Morozan, F. Jaouen, Energy Environ. Sci. 2012, 5, 9269. 
a) J. E. Mondloch, M. J. Katz, W. C. Isley lii, P. Ghosh, P. Liao, W. Bury, G. W. Wagner, M. G. Hall, J. B. DeCoste, G. W. Peterson, R. Q. Snurr, C. J. Cramer, J. T. Hupp, O. K. Farha, Nat. Mater. 2015 , 14, 512-516; b) O. T. Wilcox, A. Fateeva, A. P. Katsoulidis, M. W. Smith, C. A. Stone, M. J. Rosseinsky, Chem. Commun. 2015, 51 14989-14991; c) L. M. Rodríguez-Albelo, E. López-Maya, S. Hamad, A. R. Ruiz-Salvador, S. Calero, J. A. R. Navarro, Nature Commun. 2017, 8, 14457; d) E. Barea, C. Montoro, J. A. R. Navarro, Chem. Soc. Rev. 2014, 43, 5419-5430; e) J. B. DeCoste, G. W. Peterson, Chem. Rev. 2014, 114, 5695-5727.

a) G. W. Peterson, G. W. Wagner, A. Balboa, J. Mahle, T. Sewell, C. J. Karwacki, J. Phys. Chem. C 2009, 113, 13906-13917; b) M. J. Katz, A. J. Howarth, P. Z. Moghadam, J. B. DeCoste, R. Q. Snurr, J. T. Hupp, O. K. Farha, Dalton Trans. 2016, 45, 4150-4153. a) J. An, S. J. Geib, N. L. Rosi, J. Am. Chem. Soc. 2009, 131, 8376-8377; b) J. An, S. J. Geib, N. L. Rosi, J. Am. Chem. Soc. 2010, 132, 38-39; c) J. An, N. L. Rosi, J. Am. Chem. Soc. 2010, 132, 5578-5579.

[24] a) M. Leroux, N. Mercier, M. Allain, M.-C. Dul, J. Dittmer, A. H Kassiba, J.-P. Bellat, G. Weber, I. Bezverkhyy, Inorg. Chem. 2016, 55, 8587-8594; b) T. Grant Glover, G. W. Peterson, B. J. Schindler, D. Britt, O. Yaghi, Chem. Eng. Sci. 2011, 66, 163-170.

[25] The presence of the $\mu_{3}-\mathrm{OH}$ groups was confirmed by the bond valence sum calculation: $s=\operatorname{sum}\left(s_{i j}\right)=\operatorname{sum}\left[\exp \left(R_{i j}-d_{i j}\right) / b\right]$, where $R_{i j}$ $=1.649$ for $\mathrm{Cu}(\mathrm{II})-\mathrm{O}, d_{i j}$ is the $\mathrm{Cu}(\mathrm{II})-\mathrm{O}$ bond distances, $b=0.37$. The value obtained was 1.23. For $\mathrm{O}$, a value of $0-0.4$ indicates $\mathrm{H}_{2} \mathrm{O}, 1-1.4$ indicates $\mathrm{OH}$, and 1.8-2.2 indicates $\mathrm{O}^{2-}$.

[26] A. L. Spek, Acta Cryst. C 2015, 71, 9-18.

[27] H. Cheng, F. Huq, M. Farhad, Asian J. Chem. 2005, 17, 1532 1538.

[28] a) J. Juan-Alcañiz, J. Gascon, F. Kapteijn, J. Mat. Chem. 2012, 22 10102-10118; b) S. Rezaei, A. Landarani-Isfahani, M. Moghadam, S. Tangestaninejad, V. Mirkhani, I. Mohammadpoor-Baltork, RSC Adv. 2016, 6, 92463-92472; c) M. B. Boroujeni, A. Hashemzadeh, A. Shaabani, M. M. Amini, Appl. Organometal. Chem. 2017, e3715. a) M. Dincă, A. Dailly, Y. Liu, C. M. Brown, D. A. Neumann, J. R. Long, J. Am. Chem. Soc. 2006, 128, 16876-16883; b) P. Manna, J. Debgupta, S. Bose, S. K. Das, Angew. Chem. Int. Ed. 2016, 55 2425-2430; c) C. Xu, D. Mochizuki, Y. Hashimoto, T. Honda, Y Tsukahara, T. Yamauchi, Y. Wada, Eur. J. Inorg. Chem. 2012, 2012, 3113-3120; d) R. Sen, S. Koner, A. Bhattacharjee, J. Kusz, Y. Miyashita, K.-I. Okamoto, Dalton Trans. 2011, 40, 6952-6960. 


\section{Entry for the Table of Contents}

\section{COMMUNICATION}
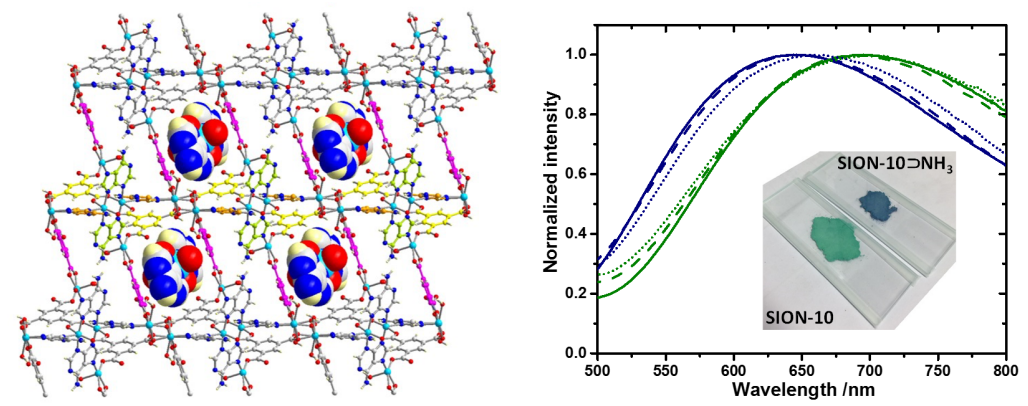

Andrzej Gładysiak, Tu N. Nguyen, Jorge A. R. Navarro, Matthew J. Rosseinsky, and Kyriakos C. Stylianou*

Page No. - Page No.

A Recyclable Metal-Organic Framework as a Dual Detector and Adsorbent for Ammonia

Response to Ammonia. SION-10, a water stable and porous ship-in-a-bottle structure, uptakes $\mathrm{NH}_{3}$ spontaneously and displays high sensitivity toward this hazardous gas. The SION-10د $\mathbf{N H}_{3}$ can be easily regenerated and recycled for at least three times. 